\title{
SOME FORMS OF UNDIAGNOSED CORONARY DISEASE IN NINETEENTH-CENTURY ENGLAND*
}

by

\author{
A. D. MORGAN
}

FOR MANY years the increased incidence of ischaemic heart disease has been the starting-point for researches into those altered factors in our way of life, our diet or our environment which are today held responsible for the enormous mortality of coronary occlusion. Recently this basic assumption has been challenged by Campbell ${ }^{1}$ (1963) and Robb-Smith ${ }^{2}$ (1967) who present plausible arguments for believing that (in this country, anyway) there has been no actual increase in incidence, and that the increase in diagnosis is due to a rise in the expectation of life, to modifications in the classification of mortality statistics, and to changes in the nomenclature of disease.

If they are right (and there seems to be no way of proving the point one way or the other) there is some value, as well as interest, in looking a little more closely at the more fully documented case reports published a century ago by some of the cream of the medical profession.

ANGINA PECTORIS, 1768-1816

The early observations of Heberden, Fothergill and Jenner in the latter part of the eighteenth century are too well known to require reiteration, and by the end of the

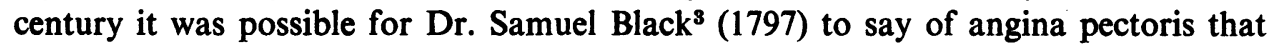
'the primary and original cause of the disorder is, perhaps, in every instance the ossification of the coronaries'. He attributed the failure of others to discern this in the following words: 'The coronaries are small vessels, and they do not lie altogether superficial, but are, in some degree, buried in the substance of the heart, for which reason I think it very possible that their condition might pass unobserved, even by a very accurate dissector, if he were not particularly apprized of the necessity of attending minutely to that circumstance'.

Twenty years later ${ }^{4}(1816)$ he related angina pectoris to obesity and plethora and prescribed an abstemious regime for his patients. He also observed that 'there is nothing in the history of this disease more remarkable, or to me more inexplicable, than the exemption of the female sex from its attacks'.

\section{$1816-1846$}

Although these observations were presented to the Medico-Chirurgical Society of London, which boasted men of the calibre of Abernethy, Bright, Brodie and Parkinson, interest in angina pectoris seems to have flagged-in Britain, at leastduring the next thirty years. Jenner's theory relating angina pectoris to coronary disease was criticized both at home and abroad, and it was shown that coronary

*Lecture to the Medico-Chirurgical Society of Aberdeen, 4 May 1967. 


\section{Undiagnosed Coronary Disease in Nineteenth-Century England}

ossification might exist in some subjects without angina, while others with angina might have normal coronaries at autopsy. Corrigan's ${ }^{5}$ observation in 1837 that anginal pain might accompany syphilitic aortitis (which spares the coronary arteries apart from their narrowed ostia) was bound to increase the confusion.

The Lancet, launched in 1823, is a fair indication of the trend, since the proceedings of most of the medical societies in the country, and a number of those abroad, were reported in its columns, and up till 1850 it is clear that general medical interest lay elsewhere than in the manifestations of ischaemic heart disease. Sundry reports appeared on sudden death, rupture of the heart, or cardiac aneurysm-all complications of ischaemic heart disease-but no one seems to have looked at the coronary arteries in these cases. Indeed, in some bound volumes of the Lancet the word 'Heart' does not appear in the index at all.

Rupture of the heart, being a spectacular mode of death, continued to attract some attention but observations such as that of Hodgson $^{6}$ (1815), who found the lesion associated with a calcified and obstructed left coronary artery, were quite exceptional. A few others observed a change in the colour or consistency of the heart muscle surrounding the tear, expressed variously as soft, flabby, flaccid, fragile, easily torn; or pale, yellow or brown. This clearly was due to the recent infarct that preceded the rupture.

A noteworthy example was Dr. Charles Williams? of the Brompton Hospital. In his Pathology and Diagnosis of Diseases of the Chest, published in 1840, he says, 'A pallid yellowish appearance of the substance of the heart is not at all an uncommon [my italics] accompaniment of other lesions of the organ, especially adhesions of the pericardium and accumulations of fat; but $I$ should be inclined to refer this to an altered state of the nutrition of the organ, owing perhaps to partial obstructions in the coronary vessels, rather than to the immediate influence of inflammation.'

This is a tentative conception of myocardial infarction, although the word was not then used. Today we all know that recent myocardial infarcts are usually pale and yellowish, and that in the course of necrosis a type of fatty degeneration occurs. In this way, as we shall see later, infarction came to be confused with fatty degeneration.

The word 'infarct' is not listed in the index of Carl Rokitansky's great Manual of Pathological Anatomy, ${ }^{8}$ published in Vienna between 1841 and 1846 . But in the section on heart disease he says, 'Among the morbid conditions predisposing to rupture we must place the various fatty conditions of the heart . . . in which the muscular substance ... assumes a dirty yellowish discolouration, may be easily torn, and becomes loose and flabby'. He developed the concept of Laënnec ${ }^{9}$ (1821) that separated fat on the surface of the heart from true fatty degeneration, and noted that in the latter, fatty globules are seen microscopically within the muscle-fibres, which also may show loss of striations. 'Considerable interest attaches itself to a not unfrequent combination of these two forms of adiposity of the heart, in which there is atheromatous disintegration and ossification of the morbidly deposited layers of the inner coat of the arteries ... These fatty degenerations are, however, very frequently associated with ossification of the coronary arteries' [my italics].

In thus linking coronary occlusion with myocardial degeneration. Rokitansky 


\section{A. D. Morgan}

was surely basing his observations on recent myocardial infarcts, of which the foregoing is no bad description.

Although not expressly linked with angina pectoris, thrombosis or infarction, the attempt of Bizot $^{10}$ (1837) to present a statistical account of coronary disease is highly relevant. He distinguished lésions primitives from lésions consécutives as we should today distinguish fatty streaks from advanced atherosclerosis. He performed 128 dissections and his tables may be summarized thus: early coronary lesions were present in about 30 per cent of subjects below the age of sixty, thereafter increasing up to 100 per cent in octogenarians. Advanced lesions were rare before forty, and thereafter increased to affect 50 per cent. Coronary ossification was more common in males, and involved the left coronary artery more than the right.

\section{THE PATHOLOGICAL SOCIETY OF LONDON}

Rokitansky's Manual had an enormous influence on his contemporaries, and it may be partly on this account that in 1846 a group of London physicians, headed by the same Dr. Charles Williams to whom I have already referred, and Dr. Benjamin Babington of Guy's Hospital, circulated the profession 'at large', inviting support for a Society dedicated to the advancement of pathology.

At the first meeting of the Pathological Society of London on 20 October 1846, 106 names were enrolled, said 'to represent various Hospitals and Medical Schools of the Metropolis, and to embrace all ranks of the profession'. Williams was its first President, and among its original members were some familiar names, for example Dr. Henry Bence Jones, who read the very first paper to the Society on 'Meningeal Apoplexy'. Another was Richard Bright. In the select list of Honorary Members was Rokitansky himself, at that time Professor of Pathological Anatomy in the University of Vienna. Many years were to pass before similar posts were instituted in this country, and one must remember that the London group consisted of physicians, surgeons, anatomists and general practitioners.

Meetings were held fortnightly, from October to May, and the Transactions were published annually, each volume stamped with a gilded bust of Matthew Baillie, the father of British pathology. Most of the Transactions consist of case-histories with autopsy reports, and morbid specimens, and a noteworthy item in the Regulations reads, 'In the remarks made in reference to Specimens exhibited, all discussions on abstract points shall be as far as possible avoided; and the topics of Diagnosis and Treatment shall not be introduced farther than is necessary to illustrate the Pathology of the Subject'. What lay behind this, I cannot say, but it has the great advantage that the published Transactions concentrate on factual data rather than theories. The Society grew and prospered, right up to 1907, when it was dissolved to constitute henceforth the Pathological section of the Royal Society of Medicine. The fifty-eight volumes which it produced, however, form the most valuable single guide to British pathology in the nineteenth century.

The published Transactions were grouped under the various systems, and in the first season, in the Circulatory Section, there were thirty-one heart cases, of which fifteen were congenital anomalies, eleven valvular disease, two which I cannot identify, and three of what appear to be ischaemic heart disease. One of these was presented 


\section{Undiagnosed Coronary Disease in Nineteenth-Century England}

at the very first meeting of the Society and related to 'a gentleman, aged 72 , fat and unaccustomed to take exercise [who] had suffered for some time from shortness of breath and pain in the chest. He went to bed in his usual state of health, was seen asleep at 3 o'clock in the morning, and was found dead at seven'. Autopsy revealed a haemopericardium from a ruptured left ventricle, and the coronary arteries were diseased, but what makes the case historically significant is the comment, 'The heart had undergone the fatty degeneration'.

\section{QUAIN'S FATTY DEGENERATION-1850}

The author was Dr. Richard Quain, ${ }^{11}$ an important figure in the history of ischaemic heart disease. He was born in Cork in 1800 and was a brother of Jones Quain, the author of a well-known textbook of anatomy. At the age of thirty Richard became Professor of Anatomy at University College Hospital, and at forty-eight was to become Professor of Clinical Surgery. Such was his versatility, however, that his main interest in 1850 was fatty degeneration of the heart and its relation to coronary disease. So successfully did he identify himself with this theme that it became known for a time as 'Quain's Fatty Degeneration'. His main thesis was that coronary occlusion leads to fatty degeneration, which may result in sudden death, rupture of the heart or cardiac aneurysm. It will be recalled that Rokitansky had mentioned, without developing the idea, an association between fatty degeneration and coronary ossification, but Quain carried the idea much further.

In 1850 he wrote a classic paper ${ }^{12}$ on the subject, and one notes with surprise that although his paper is remarkable for the generosity and detail of its referencesfor example, he throws a respectful bouquet to Dr. Charles Williams for his rather vague comment on fatty hearts and coronary obstruction-nowhere does he mention Rokitansky's contribution. Indeed, he quotes him in other contexts, only for the purpose, it would seem, of exposing his errors. Quain and Williams were friends, and Rokitansky was an Honorary Member of the Pathological Society, so presumably they knew each other's work. Perhaps Quain thought Rokitansky had taken the idea from Williams without acknowledgment. Perhaps Rokitansky borrowed it from Quain himself, before the latter went into print. We shall never know. It may be relevant to add that Quain's genius is acknowledged by the National Dictionary of Biography ${ }^{13}$ (1896), which regretfully says, 'His character was marred by the violence of his party feelings, his jealousy, and the readiness with which he imputed improper motives to all who differed from him'.

To return to Quain's paper, it occupies seventy-five pages, with copious footnotes, thirty pages of protocols, paintings of specimens and lithographs of the microscopy. He reviewed no less than eighty-three cases of fatty heart, arranged in three groups: (1) 33 cases of 'fatty degeneration', 25 of them from first hand knowledge. (2) 35 from the nineteenth-century literature, where the heart was described as being flabby, friable or fatty. (3) 15 dubious cases going back to the early eighteenth century, with record of an excessive amount of fat on the heart surface. Most of these are valueless to the reviewer, as their authors clearly had no conscious apprehension of the significance of coronary disease.

Of course a large proportion of Quain's eighty-three cases were not infarcts. $\mathrm{He}$ 


\section{A. D. Morgan}

begins by differentiating 'fatty growth' - today we should call it fatty infiltrationfrom true fatty degeneration. He further subdivides fatty degeneration into a generalized type (such as we used to see in severe anaemias or certain poisonings) and 'fatty degeneration connected chiefly with a local modification of nutrition'-the result of coronary obstruction, and surely (though the term was not in use) recent infarcts. Figure 1 is a lithograph from Quain's article, showing a microscopic view of normal and fatty myocardial fibres (unstained). For comparison I have appended a photomicrograph of a frozen section from a recent myocardial infarct, with the fat droplets stained by modern methods (Fig. 2). Quain quotes as evidence, Bizot's finding (see above) that coronary ossification is commoner in males, rare before forty, and most severe in the left coronary artery; and he points out that the sexincidence, age-group and distribution of localised degeneration follow a similar pattern.

Noting that fatty degeneration frequently occurs in hypertrophied hearts, he suggests that the hypertrophy may be 'the result of a natural effort to compensate for loss of power'. Some cases may well have been hypertensive, but normotensive coronary subjects very frequently have cardiac hypertrophy, for reasons unknown, and this was not a bad suggestion.

I have examined the clinical and pathological data of Quain's eighty-three cases, and think that fifty-two of them are likely to be ischaemic heart disease (see Table).

\begin{tabular}{|c|c|c|c|c|c|c|}
\hline Series & $\begin{array}{l}\text { No. of } \\
\text { Cases }\end{array}$ & $\begin{array}{l}\text { Male | } \\
\text { Female }\end{array}$ & $\begin{array}{c}\text { Age } \\
\text { Group }\end{array}$ & \begin{tabular}{|} 
Previous \\
chest \\
pain
\end{tabular} & Mode of death & $\begin{array}{l}\text { Cor. Disease } \\
\text { at P.M. }\end{array}$ \\
\hline I & 23 & $20 / 3$ & $47-88$ & 10 & $\begin{aligned} & 14 \text { Sudden } \\
& 4 \text { Rupt. heart } \\
& 3 \text { Rapid (11-18 hrs. } \\
& \text { prostration or coma) } \\
& 2 \text { cardiac failure }\end{aligned}$ & $\begin{array}{l}13 \text { definite } \\
9 \text { not exam. } \\
1 \text { doubtful }\end{array}$ \\
\hline II & 21 & $9 / 12$ & $50-90$ & 11 & $\begin{array}{l}6 \text { sudden } \\
14 \text { Rupt. heart } \\
1 \text { cardiac failure }\end{array}$ & $\begin{array}{l}6 \text { definite } \\
2 \text { 'coronaries } \\
\text { healthy' } \\
13 \text { not exam. }\end{array}$ \\
\hline III & 8 & $7 / 1$ & $50-77$ & 6 & $\begin{array}{l}7 \text { sudden } \\
1 \text { Rupt. heart }\end{array}$ & $\begin{array}{c}3 \text { definite } \\
\text { (Parry's } \\
\text { series) } \\
5 \text { not exam. }\end{array}$ \\
\hline TOTAL & 52 & $36 / 16$ & $47-90$ & 27 & $\begin{array}{l}27 \text { sudden } \\
19 \text { Rupt. heart } \\
3 \text { Rapid death } \\
3 \text { card. failure }\end{array}$ & $\begin{array}{l}22 \text { definite } \\
27 \text { not exam. } \\
2 \text { 'healthy' } \\
1 \text { doubtful }\end{array}$ \\
\hline
\end{tabular}

He drew attention to the relation of coronary disease to both angina pectoris and fatty degeneration, and among the various effects of the latter he lists dyspnoea, 

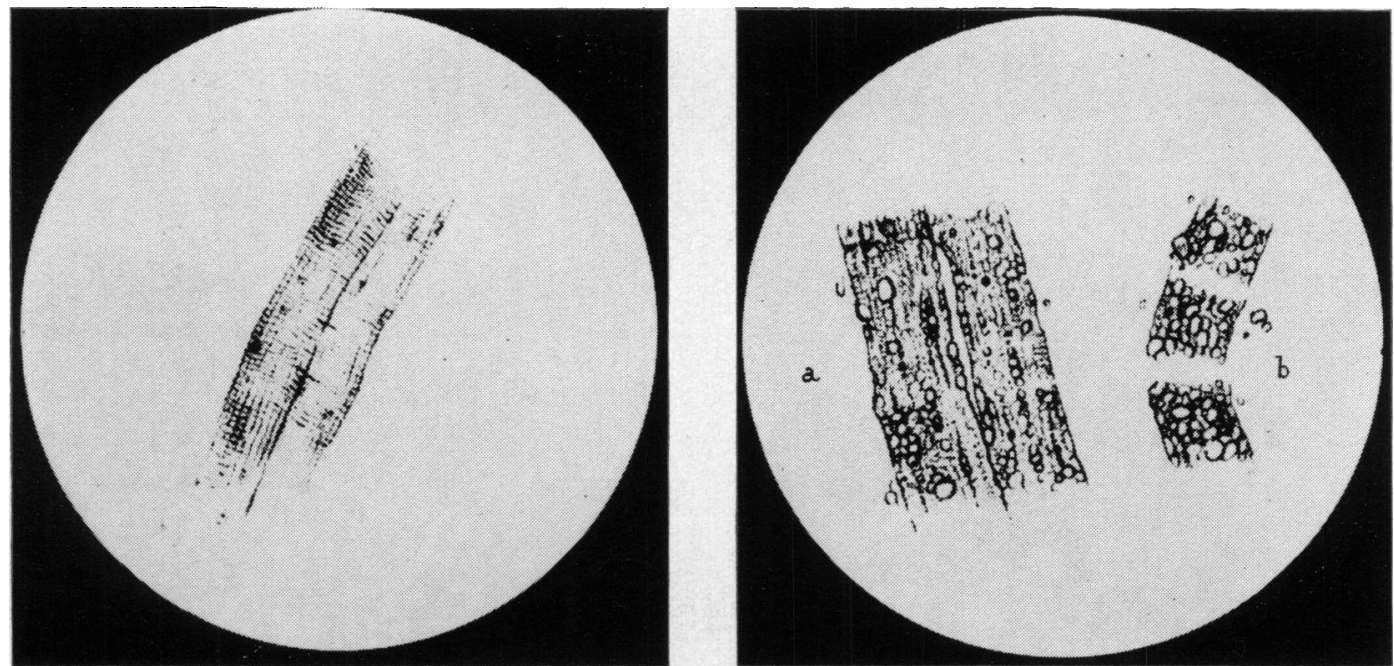

Figure 1.

Microscopic appearances of heart muscle (unstained): normal fibres (left) and fatty degeneration (right), early and late stages of which are marked a and b. (From Quain, R., Med.-chir. Trans., 1850, 33, Plate III).

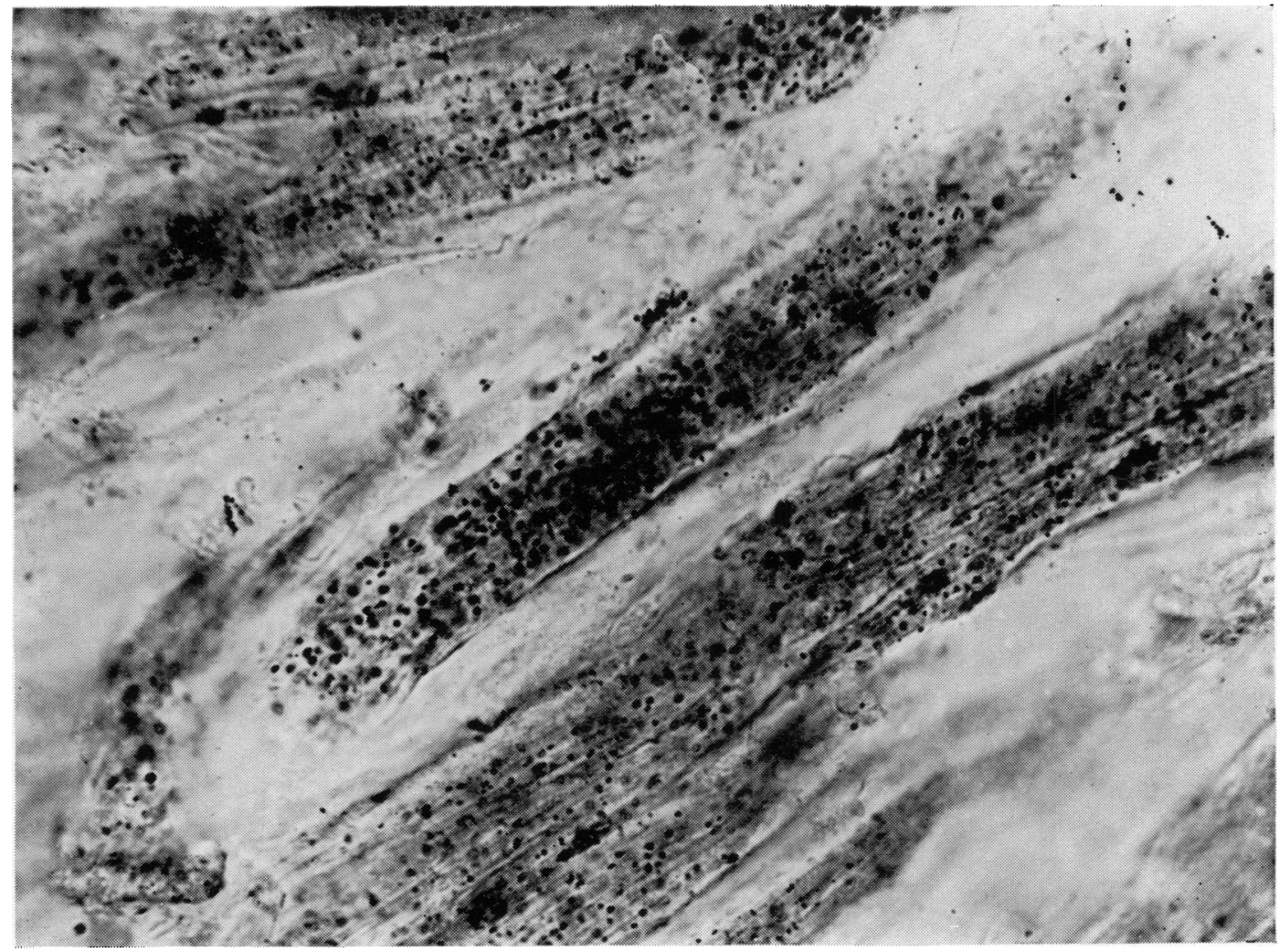

Figure 2.

Photomicrograph of recent myocardial infarct showing fatty droplets and loss of striations in the muscle fibres. Frozen section stained Oil red 0 x 710. 


\section{Undiagnosed Coronary Disease in Nineteenth-Century England}

chest pain (especially where there is rupture of the heart), slowness or irregularity of the pulse, oedema of the legs, and altered heart sounds due to dilatation of the ventricle. He had little to offer in the way of treatment, and in his closing sentences he referred to fatty degeneration as 'a disease which has hitherto almost escaped observation'.

There was no doubt that the lecture was a hit, and the Lancet ${ }^{14}$ reported thus: 'The communication ... was listened to throughout with the greatest attention, and at its close the fellows expressed their high opinion of its merits by the unusual compliment of warm applause. Many felt that the meeting might have been prolonged with advantage, so as to have afforded an opportunity for discussing this new and important subject'.

If I seem to have dwelt unduly on Quain, it is because he is important for our purpose, which is not so much to show who was first in the field, but to arrive at some sort of idea of the frequency of ischaemic heart disease in England in the nineteenth century. Certainly fatty degeneration became a popular diagnosis, so much so that it infiltrated everyday speech and even mid-Victorian literature. Indeed it was still current among the lay public in the writer's infancy. And if, in Quain's very respectable series of fatty hearts, a substantial proportion were in fact cases of myocardial infarction, it is reasonable to suppose that a substantial proportion of the returns of deaths from fatty degeneration may also have been cases of ischaemic heart disease. The great pity is that fatty degeneration was not listed in the Registrar General's Report until fifty years later.

\section{FATTY DEGENERATION, 1848-1855}

For some years Quain continued to ride his hobby-horse, and most of the Quaintype fatty hearts exhibited at the Pathological Society of London were first sent to him for vetting. Any modern pathologist reading the protocols in the Transactions would need little persuasion that Quain's fatty degeneration was none other than recent infarction, with or without cardiac rupture. This will be made apparent by quoting a few cases as briefly as is consistent with lucidity.

Take, for instance, the case of Dr. Thomas Peacock ${ }^{15}$ of St. Thomas's Hospital. A woman aged sixty suffered from dyspnoea, dependent oedema and pain in the heart region, 'accompanied with faintness and a feeling of impending death'. At autopsy the heart weighed $14 \mathrm{oz}$., the orifice of the $R$. coronary artery was constricted and 'the $\mathbf{L}$. coronary artery was converted into a cylinder of bone, for an inch and a half from its origin, and its cavity was entirely obstructed by a plug of decolourized, and evidently old lymph'. The walls of the ventricles showed fatty degeneration. Presumably the 'old lymph' was decolourized thrombus, for the red colour fades in the course of a week or two.

Mr. John Avery' ${ }^{16}$ of Charing Cross Hospital sent a heart to Quain from a heavilybuilt man of seventy-six, brought in dead, due to rupture of the $L$. ventricle, and haemopericardium. There was fatty degeneration of the left ventricle with a loss of 'cross-markings' of fibres, and 'the left coronary artery going direct to the seat of the degeneration was extensively ossified'.

At the same meeting Quain ${ }^{17}$ referred to another case, aged fifty-three, 'a stout, 


\section{A. D. Morgan}

corpulent man, a gate-porter at an hospital, unaccustomed lately to any active exertion'. He 'had suffered from pain in the chest, shooting down the L. arm on any excitement'. He later complained of umbilical pain and died suddenly. At autopsy 'the L. ventricle [was] flabby, of a dusky brownish-red colour, mottled with minute yellow spots ... The L. coronary artery was much diseased and obstructed'.

The disease was no respecter of persons, witness Quain's' ${ }^{18}$ case of 'Lady Haged 58 [who] on rising from bed . . . went to the night chair for the purpose of emptying her bladder, then laid down again and died immediately'. Recently she had had chest pains, and the fatty state of her heart was diagnosed during life because of (among other things) her sedentary habits and the presence of an arcus senilis. At autopsy 'the anterior branch of the L. coronary artery was extremely ossified', and the anterior wall and apex of the L. ventricle 'presented the pale buff colour of fatty degeneration', contrasting with the healthy flesh colour of the rest of the heart. The case is notable for the fact that 'there existed also a large quantity of a fibrous texture mixed with the degenerated muscle fibre'. More will be said about this phenomenon under 'Fibroid Degeneration'.

A few weeks later Dr. Beith ${ }^{19}$ of the Greenwich Hospital showed, with Quain's help, the case of a man of seventy-nine with frequent pain in the region of the heart. Following a sense of constriction in the chest, he collapsed suddenly and died two days later. Autopsy showed rupture of the interventricular septum, an enlarged heart $(17 \mathrm{oz}$.) 'and very dense ossification and obstruction of the portion of the coronary artery leading directly to the seat of the rupture ... There existed fatty degeneration of the muscular fibres of both ventricles ... but not in a marked degree, except near the immediate seat of the rupture... The connection between obstruction of the coronary artery and local fatty degeneration was very beautifully illustrated in this specimen'.

That same year Quain ${ }^{20}$ described the case of 'a lady of rank' aged sixty-eight, and very fat. She gave a history of substernal oppression, and her pulse was frequently irregular. Following what was taken for a gastric upset she died suddenly. Autopsy revealed a ruptured left ventricle, and in the neighbourhood of the rupture, and onwards to the apex, the muscular fibre had undergone fatty degeneration to a very marked degree ... It was of interest to observe, that other parts of the heart showed the muscular fibre in a remarkably healthy condition. There was thus, in fact, almost a local or circumscribed degeneration, which ... . was connected with a branch of the coronary artery distributed to this part of the heart, which was nearly occluded by a calcareous degeneration of its coats ... It was likewise a good illustration of the connection between rupture of the heart and fatty degeneration of the fibre'. Quain exhorted his colleagues to give more attention to symptoms and precautionary measures which would reduce mortality, 'which had been made painfully familiar [my italics] to the public by several remarkable instances of the occurrence of this calamity during the last few months'.

At the next meeting Dr. Baly ${ }^{21}$ of the Millbank Penitentiary, described yet another cardiac rupture in a fat women of fifty-two. He notes that the coronary arteries are thickened, but free from obstructions, 'except one branch of the L. coronary artery ... All its coats appeared to be thickened, and were opaque, yellow and rigid; its cavity 


\section{Undiagnosed Coronary Disease in Nineteenth-Century England}

was filled with a firm and nearly black coagulum [my italics] . . . It seemed to be obliterated at the very margin of the degenerated part of the ventricle', which microscopically showed fatty degeneration. Surely this is an early account of recent coronary thrombosis.

In its first ten years twenty-two of the 122 hearts shown (or 18 per cent) were of this type. Thus Dr. Bristowe ${ }^{22}$ who combined the duties of Assistant Physician and Demonstrator in Morbid Anatomy at St. Thomas's Hospital, described three cases in 1854, occurring within a short time of one another. Referring to one of them he says, 'The case ... . is one of that common class of which so many specimens have been brought under the notice of the Society' [my italics].

Before leaving these twenty-two hearts, by the way, we may note that increased weight was recorded in nine of them, associated cardiac aneurysm in three and myocardial fibrosis in one.

One would have thought that Quain had established his case, but the lamentable tendency to stray from the path of righteousness was all too soon in evidence. As early as 1855 Dr. William Cholmeley ${ }^{23}$ of the West London Dispensary put the cart before the horse, without improving the view of his fellow-travellers. He records that: 'Sir J. M., aet 48, a Scotch gentleman, arrived in Town on 31 January, in apparently excellent health, having only a slight cough. Next morning, immediately after a hearty breakfast, he went out, and after a few minutes fell insensible in the street. He was seen, within two minutes, by Mr. Moore of the Middlesex Hospital, but was already dead'.

Autopsy showed that he was a stout, fat man with an arcus senilis. The heart was enlarged by a pouch (i.e. aneurysm, of which more later) at the apex lined by 'a gritty, opaque, fibrinous coagulum ... The coronary arteries were thick-walled and rigid, but permeable. Under the microscope the altered tissue of the heart presented all the usual appearances of the fatty degeneration'.

It was subsequently learned that Sir J. M. had suffered from 'attacks resembling angina pectoris' for five years-note the early onset at forty-three-but in recent months his symptoms had practically disappeared, 'so that he had resumed an active country life: was able, without discomfort, to shoot over Scotch ground; and was, at the time of his death, engaged to return North to a curling match'.

Alas! After this lively account the good doctor says, 'The cause of the fatty degeneration of the heart was, in this case, I think, the attack of inflammation which left an adherent pericardium; the general nutritive power of the system was already imperfect, as is shown forth in the gouty diathesis. By the attack of inflammation the part so affected was further weakened, so that degeneration of its tissues followed. The diseased condition of the coronary arteries may be thus considered as one among the consequences of the inflammation, rather than as itself the cause of the fatty degeneration'.

Thus, five years after Quain's classic, based on eighty-three cases, we have the alltoo-familiar spectacle of the sturdy individualist waffling and theorising on the basis of his solitary experience.

CARDIAC ANEURYSM, 1838-1854

There are, of course, manifestations of ischaemic heart disease other than sudden 


\section{A. D. Morgan}

death, recent infarction or cardiac rupture, and these may be summarized by considering very briefly the immediate and delayed effects of coronary occlusion. Following coronary thrombosis, collateral circulation may be adequate, leaving the myocardium intact; or inadequate, in which case infarction ensues. Death may occur at this stage from cardiac arrest, cardiac rupture or rapid cardiac failure.

Organization and recanalization of the thrombus, in those cases that survive, leads to coronary stenosis, and if the collateral circulation had been adequate throughout, again the myocardium is intact, but sudden death in such cases is common, as every pathologist knows. Healed infarcts, on the other hand, lead to scarring, followed by heart-block, cardiac failure, cardiac aneurysm, or the delayed effects of embolism from the seat of infarction.

Thus, the findings at autopsy will be thrombosis or stenosis in the coronary arteries, and a myocardium which may show nothing at all, recent infarction, left ventricular rupture, healed infarction, or aneurysm, with or without cardiac hypertrophy, with or without signs of cardiac failure.

The ones we have not met with so far are aneurysm and fibrous scarring. Most pathologists would agree that aneurysms of the left ventricle, and large fibrous scars, are now, and were then, commonly the result of ischaemic heart disease. There is a tendency to attribute much of Victorian pathology to the ravages of syphilis, but a modern morbid anatomist, reading the contemporary accounts of cardiac aneurysm and fibrosis, would not agree that such a conclusion was justified.

Reports of isolated cases of cardiac aneurysm go back a long way, and many dating from the early seventeenth century were reviewed in 1838 by John Thurnam, ${ }^{24}$ at that date at Westminster Hospital. These records were made dubious by the confusion in older writings between aneurysm and simple distension of one chamber of the heart, and Thurnam rendered a service by distinguishing true aneurysms due to disease of the heart wall, from mere functional dilatations.

He personally studied thirteen cases and reviewed eighty-four in the literature, of which fifty-eight were in the left ventricle, the others being in the left atrium and heart-valves. He comments on the fact that the right ventricle is immune, that cardiac aneurysm is often associated with fibrosis, and for a moment he soared to dizzy heights by suggesting that angina pectoris, fibrosis and cardiac aneurysm all have a common cause; but this inspired comment was offset by a total failure to consider the coronary arteries at all, and by the conclusion that the fibrosis was due to inflammation (e.g. pericarditis), and anginal pain to the irritation of cardiac nerves by ossified morbid structures. Some of his fifty-eight left ventricular aneurysms may have been due to developmental defects in the interventricular septum, but the majority were probably the sequelae of old infarction.

There is an innocent credulity in his review of earlier case reports, for example: 'As regards the occupation and mode of life, out of 17 cases, all males, in which this is stated, it appears that there were one nobleman, one merchant, one tragedian, the celebrated Talma, 2 generals, one colonel, 5 private soldiers, one gondolier, one cabinet-maker, 2 tailors, and 2 victuallers. It is a striking fact that out of this number 8 ... should have been soldiers; a circumstance which would lead one to suspect that the exposure to which this class of persons is subject, and the forced exercise 


\section{Undiagnosed Coronary Disease in Nineteenth-Century England}

which they undergo, may have something to do with the production of this lesion'.

Again: 'The exciting cause of the disease would appear to have been external violence in the form of an injury to the chest in the case of the gondolier, a fit of violent anger in that of the nobleman, protracted mental anxiety in one instance, severe efforts on the stage in the character of Hamlet, in the case of Talma, and in a fifth instance, the retention of the breath during a military flogging'.

We are on firmer ground with the London Pathological Society, but it is sad to relate that the first cardiac aneurysm exhibited by Dr. William Jenner ${ }^{25}$ bore no mention of the coronary arteries. This was in 1848, before Quain had made his claim that angina pectoris, cardiac rupture and cardiac aneurysm were all due to coronary sclerosis. But a few years later Dr. Peacock ${ }^{26}$ showed the case of a sexagenarian with several weeks' history of precordial pain. The apex of the left ventricle had undergone 'fibro-cartilaginous transformation' and aneurysmal dilatation, and the coronary arteries were 'extremely diseased'.

Some of the reports which followed linked cardiac aneurysm with coronary disease, but half a dozen others ignored the vessels completely. At autopsy fatty degeneration or fibrosis of the surrounding myocardium was noted, the latter being ascribed to chronic inflammation; but what these reports lacked in factual detail, they made up for in metric imagery, recording the size of the aneurysmal cavity in terms of a plover's egg, the half of a large hen's egg, a small orange and a large coconut. But none of these can compare with the delicious reference by Thurnam to an aneurysm, the cavity of which 'would have contained a moderately sized Orleans plum'.

\section{FIBROID DEGENERATION 1851-1884}

One other cardiac lesion continued to perplex the Fellows of the London Pathological Society. This was originally described as fibrous (or fibrinous) disease (or degeneration) of the heart, in 1851-2 when three cases were shown by Drs. Bennett ${ }^{27}$ and Bird, ${ }^{28}$ and Professor Ogle ${ }^{29}$ of Oxford. A study of the autopsy reports indicates that this was a patch of fibrous tissue forming a white lesion readily visible to the naked eye, and which to modern ears sounds very much like a healed myocardial infarct.

Certainly some were not infarcts-for example, those in young women; and those of younger age-groups with valvular lesions were presumably rheumatic, although gross scarring is unusual in that condition. At first the lesions were thought to be syphilitic, but in many of the reports that followed, the absence of other luetic stigmata at autopsy was emphasized. By the way, in the sixty years of the Society's existence there is record of only one active cardiac gumma.

In an early review Ogle ${ }^{30}(1857)$ noted the frequency of alterations in the cardiac rhythm, and it happens that several of the cases under consideration had septal lesions. The epileptiform convulsions described were presumably Stokes-Adams attacks.

A glimmer of the truth came from Dr. Moxon ${ }^{31}$ (1866) who performed an autopsy at Guy's Hospital on a man who fell dead in an omnibus, due to rupture of the left ventricle. The left coronary artery showed advanced calcified atheroma, and he thought that an associated fibrous lesion in the ventricular septum was probably the 


\section{A. D. Morgan}

same as 'fibroid disease', which, he suggested, was 'none other than clots formed in the substance of the wall . . . by injury to the vessels'. Not too convincing, perhaps, but the only linkage of coronary occlusion and fibroid disease in the forty-odd case reports in the Transactions.

In a later review Dr. Hilton Fagge, ${ }^{32}$ also of Guy's Hospital, described eleven cases, six of which would pass for ischaemic heart disease; as an example take the case of a man aged forty-three, with swelling of the ankles, who died suddenly. His heart weighed $21 \mathrm{oz}$. and there was a fibrous patch $2 \frac{1}{2}$ inches wide, involving the apex and ventricular septum, which 'creaked under the scissors and was exceedingly hard and tough'. At this point the heart wall was thinned and lined by recent thrombus. Another fibrotic heart was frankly aneurysmal.

Fagge suggested that there were two broad clinical presentations in fibroid disease -sudden death and cardiac dropsy. But neither he nor any of the enthusiasts for this diagnosis ever seem to have had a good look at the coronary arteries. He drew attention to the connection between fibroid disease and cardiac aneurysm, pointed out by Quain long before, and suggested (rightly) that the one was probably the cause of the other; but he thought the fibrosis was due to 'chronic myocarditis', as did many of the leading pathologists of the day. As chronic myocarditis was to become as common in medical parlance as fatty degeneration, the point is of some importance.

Fagge observed that he had seen 11 cases in a single hospital in less than a year [my italics] admitting that this was partly due to the fact that he was looking for the scars at autopsy. If only he had looked as hard at the coronary arteries! But he did forecast that fibroid disease would 'prove to be a comparatively common cause of sudden death'.

This was confirmed a decade later by Dr. Hale White ${ }^{33}$ (again from Guy's) but once more the pendulum had swung, and he thought syphilis was a major cause of fibroid disease. In his nine cases he mentioned the coronary arteries in only one of them-to say that their orifices were 'good and patent'.

CORONARY THROMBOSIS AND MYOCARDIAL INFARCTION 1865-1880.

In fact, during the 1860 s the coronary arteries had been once more in the doldrums. For instance, a whole row of ruptured hearts had been described, but the coronary arteries-in Quain's heyday considered the key to the lesion-were not even mentioned. There was a shift in emphasis when Dr. Dickinson ${ }^{34}$ of St. George's Hospital described three cases of syphilitic aortitis in 1865 , in which the coronary orifices were nearly obliterated by the aortitis, though the rest of the vessels remained patent. One of his cases was a young soldier who died while making love to his girl friend in Hyde Park, 'the excitement being produced by a paroxysm of the disease from which he had before suffered'. Dickinson makes the interesting (and correct) observation that 'closure of the coronary vessels does not prevent considerable hypertrophy of the heart'.

But Quain ${ }^{35}$-now Sir Richard Quain-was still active though in his seventies, and in 1871 he examined the heart of a man with angina pectoris so severe that 'he had no ease from pain, except when resting on his hands and knees'. The heart showed slight fatty degeneration, and in the left coronary artery, 'about an inch from its commencement ... the vessel ... was found to contain a clot [my italics] a quarter of an 


\section{Undiagnosed Coronary Disease in Nineteenth-Century England}

inch long, which seemed adherent to its walls'.

This was Quain's last fling, but over the years he had made his point. The previous year the German pathologist Rindfleisch, ${ }^{36}$ writing of fatty softening of the heart and cardiac rupture, said, 'Atheromatous degeneration of the coronary arteries with plugging of one of their larger branches by a thrombus may be regarded in every instance [my italics] as the cause of this dangerous lesion'. A few years later his compatriot, Carl Weigert, ${ }^{37}$ wrote the first full account of the pathology of myocardial infarction, including the observation that 'destroyed muscle fibres are replaced by fibrous tissue, and the so-called chronic myocarditis is nothing else but such a process' [my italics].

Cohnheim ${ }^{38}(1882)$ agreed that 'the very great majority of . . . myocarditic indurations, . . . whether they represent the final stage of . . . so-called cardiac infarcts, or constitute the residual product of a slow ... destruction of . . . muscle fibres, are due to advanced sclerosis of the ... coronary artery. Furthermore, most pathologists are probably now unanimous in regarding numerous cases of fatty degeneration as the sequelae simply of severe coronary sclerosis'.

Before the end of the century the pathology of myocardial infarction had been fully elaborated as a thesis by René Marie ${ }^{39}$ in 1896 . Some of the truths he enunciated have been so thoroughly forgotten that it has afforded much innocent joy to later research-workers to rediscover them.

It has always been a mystery why pathologists took so long in getting round to thrombosis as a major factor in ischaemic heart disease. The fact is that only a minority of cases of ischaemic heart disease show much sign of red thrombus in the coronary arteries. Most cases of sudden death show long-standing coronary stenosis without recent thrombosis-there is no time for that to occur. A few may show rupture of the heart, or an infarct resulting from a thrombus which has changed to a brown or yellow mush, difficult to tell from 'atheroma'. When a red thrombus is seen in these cases, it may be only $2 \mathrm{~mm}$. long, and readily dislodged or overlooked.

It is usually when the patient dies in hospital some days after the attack-and such cases are less than one-third of the ischaemic heart disease the writer encountersthat one may see red thrombus in a coronary artery without difficulty. This is probably due to the fact that following the infarction the thrombus has time to spread distally for 2 or $3 \mathrm{cms}$. along the coronary artery.

After a few days it begins to lose its red colour. This offers one reasonable explanation for the delay in recognizing coronary thrombosis as the basic lesion. Indeed it is only within the last decade that J. B. Duguid ${ }^{40}$ has shown that what has been called coronary atheroma for over a century, is largely altered thrombus.

It is therefore not surprising that Dr. Samuel West, ${ }^{41}$ who incidentally was a pioneer of injection techniques which revealed abundant (and unexpected) interarterial coronary anastomoses, recognized only two thromboses in a series of twelve cases of coronary occlusion published in 1883 .

He made some other interesting observations, ${ }^{42}$ e.g. that thrombosis may in time reduce a coronary artery to a fibrous cord; that one or both coronary arteries may be greatly narrowed without producing naked-eye changes in heart-muscle; and (for our purpose highly significant) that his 'twelve cases must not be taken to represent 


\section{A. D. Morgan}

the relative rarity of the affection, for the coronary arteries are frequently overlooked [my italics] in making an ordinary post-mortem examination'.

But this takes us back to Dr. Samuel Black, and the rest of the story must necessarily be compressed. Though all of the pathology was now uncovered, it took nearly thirty years for the American doctor Herrick ${ }^{43}$ to describe the clinical picture in full, and another sixteen years for the message to get back to England.44 Even as late as 1915, Clifford Allbutt ${ }^{45}$ was insisting that angina pectoris and coronary thrombosis were different diseases.

\section{CONCLUSION}

Although ischaemic heart disease may have masqueraded in the nineteenth century as angina pectoris, fatty degeneration, rupture of the heart, cardiac aneurysm, fibroid degeneration or chronic myocarditis, there would seem to have been-to quote one of our profession's favourite phrases-'quite a lot of it about'. This is something to take into consideration when assessing the significance of hydrogenated fats and other sophisticated facets of contemporary living which are impugned as factors in ischaemic heart disease.

It is not possible, of course, to say just how common coronary disease was in the nineteenth century. Although the Registrar General's Reports go back to 1837, the only diagnosis specifically related to ischaemic heart disease was angina pectoris, which first appeared about 1850 . 'Fatty disease' is not listed until 1905, and all the other possibles-cardiac rupture, cardiac aneurysm, fibroid degeneration and myocarditis-were not listed. And it was not until after 1930 that the word 'coronary' appeared in the causes of deaths.

\section{I.H.D. $19^{\text {th }}$ Century}

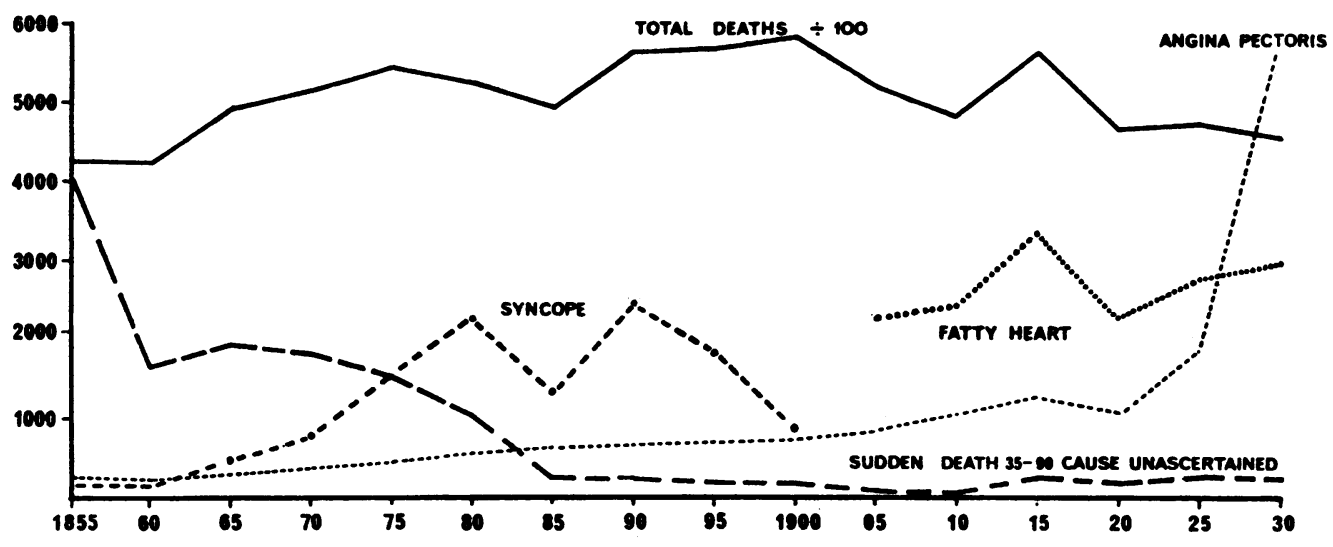

Figure 3.

Incidence of angina pectoris and other possible guises of ischaemic heart disease, 1850-1930, compiled from the Registrar General's Reports. The total death rate has been divided by 100. 


\section{Undiagnosed Coronary Disease in Nineteenth-Century England}

The graph shown in fig. 3 was compiled from the mortality of heart disease between 1855 and 1930. There is a gradual rise in the annual death rate, and angina pectoris follows a similar trend up to the end of the century, when there is a perceptible increase, followed by a spectacular rise after 1920.

The other curves relate to the only other listed causes which might conceivably be related to ischaemic heart disease. Sudden death from unascertained causes in middle and old age dropped sharply in the first thirty years of registration, presumably due to improvements in diagnosis. On the other hand 'Syncope' pursued an erratic course which can only be explained by changes of fashion in nomenclature. 'Fatty degeneration' was not listed until the turn of the century, and tended to fall off as angina pectoris increased.

The reviewer is left with the impression that, whereas all the essential data for the understanding of ischaemic heart disease had been uncovered a hundred years ago, and while now one, now the other, aspect of the process was fitfully grasped by a few, the truth was all too soon obscured by their fellows who wandered too far from the Palace of Truth.

\section{ACKNOWLEDGEMENTS}

I wish to thank Dr. F. N. L. Poynter, Director of the Wellcome Institute of the History of Medicine, for helpful advice in preparing this paper; Dr. G. W. Jewkes of the General Register Office for affording access to early death registers; and the Department of Photography, Westminster Medical School, for help with the illustrations.

\section{REFERENCES}

1. Campbell, M., (a) 'Death-rate from diseases of the heart', (b) 'The main cause of increased death-rate from diseases of the heart', Brit. med. J., 1963, ii, 528-35, 712-17.

2. Robb-Smith, A. H. T., The Enigma of Coronary Heart Disease, London, Lloyd-Luke, 1967, chapters 1 and 2.

3. Black, S., 'A case of angina pectoris, with a dissection', Mem. med. Soc. Lond., 1797, 6, 41-49.

4. BlACK, S., 'History of two cases of angina pectoris', Med.-chir. Trans., 1816, 7, 70-83.

5. Corrigan, D. J., 'On aortitis, as one of the causes of angina pectoris; with observations on its nature and treatment', Dubl. J. med. Sci., 1837, 12, 243-54.

6. Hodgson, J., A Treatise on the Diseases of the Arteries and Veins, London, 1815, case 8, pp. 39-40.

7. Williams, C., Pathology and Diagnosis of Diseases of the Chest, London, 1840, p. 245.

8. Rokitansky, C., A Manual of Pathological Anatomy, trans. by George Day, London, New Sydenham Society, 1852, vol. 4, pp. 173, 206.

9. LAËNnEC, R. T. H., A Treatise on the Diseases of the Chest (trans. John Forbes), 1821, pp. 229-30.

10. Bızot, J., 'Récherches sur le coeur et le système artériel chez l'homme', Mém. Soc. Méd. L'Observ., 1837, 1, 384-85.

11. QuaIN, R., 'Rupture of the left ventricle. Fatty degeneration of the heart', Trans. path. Soc. Lond., 1846, i, 62-63.

12. QuaIN, R., 'Fatty diseases of the heart', Med.-chir. Trans., 1850, 33, 121-96.

13. Dictionary of National Biography, London, 1896, vol. 47, p. 90.

14. Medical Societies' Reports, Lancet, 1850, i, 368.

15. Peacock, T., 'Angina pectoris dependent on disease of the coronary arteries, and fatty degeneration of the heart', Trans. path. Soc. Lond., 1849, 2, 48.

16. Avery, J., 'Rupture of the left ventricle of the heart', Trans. path. Soc. Lond., 1849, 2, 187-88.

17. QuAIN, R., 'Microscopic specimens of fatty degeneration of the heart', Trans. path. Soc. Lond., 1849, 2, 188-89. 


\section{A. D. Morgan}

18. QuaIN, R., 'Fibrous and fatty degeneration of the heart', Trans. path. Soc. Lond., $1850,3,82-85$.

19. BEITH, R., 'Rupture of the septum ventricularum, extending through the walls of the right ventricle', Trans. path. Soc. Lond., 1851, 3, 69-71.

20. QUAIN, R., 'Fatty degeneration of the heart, causing death by rupture of the left ventricle', Trans. path. Soc. Lond., 1851, 3, 262-64.

21. BaLY, W., 'Rupture of the heart, consequent on fatty degeneration, associated with softening of the brain', Trans. path. Soc. Lond., 1851, 3, 264-69.

22. BRistowe, J. S., 'Cases of fatty degeneration of the heart', Trans. path. Soc. Lond., $1854,5,83-95$.

23. Cholmeley, W., 'Fatty degeneration of the heart, with adherent pericardium and membranous pouching of the left ventricle', Trans. path. Soc. Lond., 1855, 6, 146-48.

24. Thurnam, J., 'Aneurisms of the heart', Med.-chir. Trans., 1838, 21, 187-265.

25. Jenner, W., 'Partial aneurism of the left ventricle', Trans. path. Soc. Lond., 1848, 2, 39-40.

26. Peacock, T., 'Lateral or partial aneurism of the heart', Trans. path. Soc. Lond., 1854, 5, 96.

27. BENNETT, R., 'Fibrous degeneration of, and deposits in the substance of the heart', Trans. path. Soc. Lond., 1851, 3, 273-75.

28. BIRD, J., 'Fibrous degeneration of and deposit in the substance of the heart, connected with acute rheumatism', Trans. path. Soc. Lond., 1852, 3, 276-79.

29. OGLe, J. A., 'Fibrinous deposit in the wall of the heart', Trans. path. Soc. Lond., 1852, $3,281-82$.

30. OGLE, J. A., 'Fibrinous deposit in masses within the substance of the heart's walls. Peculiarities in the pulse', Trans. path. Soc. Lond., 1857, 8, 116-18.

31. Moxon, W., 'Rupture of the heart', Trans. path. Soc. Lond., 1866, 17, 70-71.

32. FAGGe, H., 'A series of cases of fibroid disease of the heart', Trans. path. Soc. Lond., $1874,25,64-98$.

33. Hale White, W., 'Case of fibroid disease of the heart causing sudden death', Trans. path. Soc Lond., 1884, 35, 114-19.

34. Dickinson, W. H., 'Three cases of angina pectoris, depending upon occlusion of the mouths of the coronary arteries', Trans. path. Soc. Lond., 1866, 17, 53-57.

35. QUAIN, R., 'Dilatation of the arch of the aorta, and plugging and obliteration of the left coronary artery', Trans. path. Soc. Lond., 1872, 23, 57-59.

36. Rindfleish, E., A Manual of Pathological Histology, trans. by E. B. Baxter, London, New Sydenham Society, 1872, vol. 1, p. 274.

37. Weigert, C., 'Ueber die pathologischen Gerinnungsvorgänge', Virchows Arch. path. Anat. Physiol., 1880, 79, 87-123.

38. Cohnherm, J., Lectures on General Pathology, trans. by A. B. McKee, London, New Sydenham Society, 1889, vol. 1, p. 38.

39. MARIE, R., 'L'infarctus du myocarde', Paris thesis no. 88, 1896.

40. Duguid, J. B., 'Thrombosis as a factor in the pathogenesis of coronary atherosclerosis', J. Path. Bact., 1946, 58, 207-12.

41. WeST, S., 'Cases of complete obliteration of one coronary artery, with remarks upon the coronary circulation', Trans. path. Soc. Lond., 1884, 35, 110-14.

42. WEST, S., 'Complete obliteration of one coronary artery; sudden death; remarks upon the anastomosis of the coronary arteries', Trans. path. Soc. Lond., 1883, 34, 66-67.

43. Herrick, J. B., 'Clinical features of sudden obstruction of the coronary arteries', J. Amer. med. Ass., 1912, 59, 2015-20.

44. Parkinson, J. and Bedford, D. E., 'Cardiac infarction and coronary thrombosis', Lancet, 1928, i, 4-11.

45. Allbutt, T. C., Diseases of the Arteries including Angina Pectoris, London, 1915, vol. 2, p. 352 et seq. 